\title{
FORMULATION AND CHARACTERIZATION OF SUSTAINED RELEASE COATED MATRIX GRANULES OF METFORMIN HYDROCHLORIDE
}

\author{
RADHA RANI EARLE ${ }^{1 *}$, KIRAN KUMAR BANDARU ${ }^{2}$, LAKSHMI USHA A ${ }^{1}$ \\ ${ }^{1}$ Department of Pharmaceutical Technology, Maharajah's College of Pharmacy, Vizianagaram, Andhra Pradesh, India. ${ }^{2}$ Leiutis \\ Pharmaceuticals, Hyderabad, Telangana, India. Email: radhaearle@yahoo.com
}

Received: 29 January 2018, Revised and Accepted: 17 April 2018

\section{ABSTRACT}

Objective: Metformin hydrochloride is a biguanide antihyperglycemic agent which is a generally recommended first-line drug for the treatment of diabetes mellitus (Type II). The purpose of this investigation is to prepare sustained release matrix granules of metformin hydrochloride which are coated to extend the drug release over a longer time period.

Methods: Metformin hydrochloride granules were prepared by mixing all the dry powders in a V-cone blender and wetting the powder mix with aqueous solution of hydroxypropyl methyl cellulose K100. The prepared granules (MG1-MG5) were investigated for drug release. The batch of granules which exhibited extended release for up to $4 \mathrm{~h}$ was coated in a standard coating pan with blends of Eudragit RS and RL to further enhance release period. These were marked as coated metformin granules (CMG3) and CMG4 which were later filled into empty capsules. The granules were characterized for micromeritic properties, percentage yield, particle size distribution, percentage of drug content, and in vitro release of the drug.

Results: All the formulations showed percentage yield in the range of 77.66-82.86\% and drug content in the range of 78.23-96.62\%. CMG3 showed drug release of $97.02 \%$ for $12 \mathrm{~h}$. Fourier-transform infrared spectroscopy and differential scanning calorimetry studies indicated that no possible interaction existed between the drug and the polymers used. Scanning electron microscopy images revealed that the granules were spherical in shape with smooth surface and completely covered with a coating of polymer. Kinetic analysis of drug release confirmed that drug release followed zeroorder kinetics where it is independent of the concentration.

Conclusion: From the results, it was analyzed that design of coated granules employing the polymers used in the present work can produce a sustained release of the drug over a period of $12 \mathrm{~h}$.

Keywords: Metformin, Sustained release, V-cone blender, Eudragit, Standard coating pan.

(C) 2018 The Authors. Published by Innovare Academic Sciences Pvt Ltd. This is an open access article under the CC BY license (http://creativecommons. org/licenses/by/4. 0/) DOI: http://dx.doi.org/10.22159/ajpcr.2018.v11i7.24996

\section{INTRODUCTION}

The design of sustained dosage forms is to slowly release the drug over an extended time period. They possess a major advantage of improved patient compliance as the dosing frequency is once or twice daily [1]. In case of dosage forms for extended release, multiple unit forms are mostly preferred over single unit dosage forms as they contain a minute amount of the drug and thus have a lower risk of dose dumping [2].

Metformin hydrochloride (Fig. 1) is a potent antidiabetic drug with a major drawback of shorter elimination half-life $(6.2 \mathrm{~h})$. It acts in the presence of insulin to enhance glucose use and decrease the production of glucose by counteracting insulin resistance. The effect of metformin includes enhanced glucose uptake and reduced hepatic gluconeogenesis. Drugs with shorter biological half-life are suitable candidates for formulation in sustained release dosage forms [3,4].

The aim of the current investigation is to formulate coated granules of metformin hydrochloride. To overcome the drawback of shorter elimination half-life and fluctuations in plasma level concentration of the drug, an attempt was made to sustain the release of the drug by formulating it as coated granules using retardant polymers.

\section{METHODS}

Materials

Metformin hydrochloride, Eudragit RS and RL 100, and hydroxypropyl methylcellulose (HPMC) K 100M were obtained from Yarrow Chem Products, ethyl cellulose from Otto, and dicalcium phosphate and propylene glycol from Finar Chemicals.
Preparation of sustained release matrix granules Different batches of granules (MG1, MG2, MG3, MG4, and MG5) were prepared according to the composition mentioned in Table 1. Accurately weighed quantities of each component were mixed in a V-cone blender. The powder mix was wetted with an aqueous solution of HPMC K $100(7.5 \%, \mathrm{w} / \mathrm{w})$. The granules obtained after passing through a sieve ( 10 mesh size) were then dried adequately at $60^{\circ} \mathrm{C}$ for $30-45 \mathrm{~min}$. The dried granules were sifted manually through 10 mesh screen. The matrix granules in particle size range of 10-22 mesh had been selected. These batches of granules were put under physical characterization and drug release study.

\section{Coating of sustained release matrix granules}

The granules which exhibited extended release up to $4 \mathrm{~h}$ (MG3 and MG4) needed further modification to enhance release period. Matrix granules (10-22 mesh size) were coated stepwise in a standard pan coater. Metformin matrix granules were coated with blends of Eudragit ${ }^{\circledR}$ RS and RL along with plasticizer and propylene glycol (20\% w/w). All dispersions were plasticized overnight. Eudragit ${ }^{\circledR}$ RS and RL blend ratios were investigated at 85:15 (w/w), and this caused $10 \%$ weight gain in granules. After coating, these granules were marked as batch coated metformin granules (CMG3) and CMG4. Coated CMG3 batch had sustained the drug release for a longer period of $12 \mathrm{~h}$. These coated batches were later subjected to physicochemical characterization tests and in vitro release study $[5,6]$.

\section{Compatibility studies}

Fourier transform infrared (FTIR) analysis

The FTIR spectra of prepared granules were scanned over a frequency range of $4000-400 / \mathrm{cm}$. A little quantity of sample was placed on 
diamond attenuated total reflection and analyzed for the presence of characteristic peaks.

\section{Differential scanning calorimetry (DSC)}

The DSC analysis of pure drug and coated and uncoated granules was carried out to evaluate any possible drug-polymer interaction. The analysis was performed at a rate of $10^{\circ} \mathrm{C} \mathrm{min}-1$ from $20^{\circ} \mathrm{C}-30^{\circ} \mathrm{C}$ temperature range under nitrogen flow of $25 \mathrm{ml} / \mathrm{min}$ [7].

\section{Surface morphology}

The morphology of coated granules was investigated by scanning electron microscopy (SEM) at an accelerating voltage of $1.0 \mathrm{kV}$.

\section{Characterization of granules}

\section{Determination of micromeritic properties}

The granules were characterized for their bulk density, tapped density, compressibility index, Hausner's ratio, and angle of repose [8]

\section{Percentage yield (\% yield)}

It is the weight of final product after drying to the initial weight of drug and polymer used for preparation of granules. The percentage yield was calculated using the following formula:

$\begin{aligned} \text { Percentage yield }(\%)= & \frac{\text { Weight of the granules }}{\text { Total weight of the drug }} \times 100 \\ & \text { and polymer taken }\end{aligned}$

\section{Estimation of drug content}

A weighed quantity of granules (equivalent to $100 \mathrm{mg}$ of a drug) was crushed into powder and added to $100 \mathrm{ml}$ of $\mathrm{pH} 6.8$ phosphate buffer. The resulting mixture was stirred for $2 \mathrm{~h}$ and kept overnight. Then, the

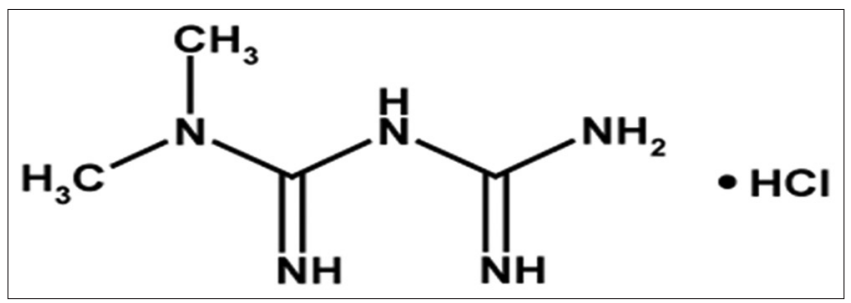

Fig. 1: Structure of metformin hydrochloride solution was filtered through the Whatman's filter paper, and $1 \mathrm{ml}$ of this solution was diluted using $\mathrm{pH} 6.8$ phosphate buffer and analyzed spectrophotometrically at $235 \mathrm{~nm}$ to get practical drug content.

Drug entrapment efficiency $(\%)=\frac{\text { Practical drug content }}{\text { Theriotical drug content }} \times 100$

Determination of particle size distribution by sieve analysis

A mechanical sieve shaker was employed for partitioning the granules into different size meshes. A stack of 5 numbers of standard stainless steel sieves (Ajantha Sieves, Chennai, India) were placed in a sequence of their increasing pore size (bottom to top) over a sieve shaker. Accurately $10 \mathrm{~g}$ of granules from different formulated batches were loaded on the topmost sieve. Then, the sieve shaker was operated for a 10 min period. Granules retained over each sieve were collected and weighed accurately [9].

\section{In vitro drug release studies}

The in vitro drug release studies were performed using USP dissolution apparatus. The dissolution medium consisted of $\mathrm{pH} 6.8$ phosphate buffer $(900 \mathrm{ml})$ and was maintained at $37 \pm 0.5^{\circ} \mathrm{C}$. At specified time intervals, $5 \mathrm{ml}$ aliquot was withdrawn and immediately replaced with the same volume of fresh buffer maintained at the same temperature. The drug release was determined using ultraviolet-visible spectrophotometer at $235 \mathrm{~nm}$. The dissolution studies were conducted in triplicate, and the mean percentage cumulative drug release was plotted against time of drug release [10].

\section{Kinetics of drug release}

Mathematical modeling is a significant approach in the optimization of a formulation because its development utilizes comprehension of all the parameters affecting drug release kinetics. The various modeldependent approaches include zero-order, first-order, Higuchi, HixsonCrowell, and Korsmeyer-Peppas.

$\mathrm{Q}_{\mathrm{t}}=\mathrm{Q}_{0}+\mathrm{k}_{0} \mathrm{t}$

$\log Q=\log Q_{0}-k t / 2.303$

$\mathrm{Q}_{\mathrm{t}}=\mathrm{k}_{\mathrm{HC}^{*}} \mathrm{t} 1 / 2$

$\mathrm{Qo}^{1 / 3}-\mathrm{Q}^{1 / 3}=\mathrm{kt}$

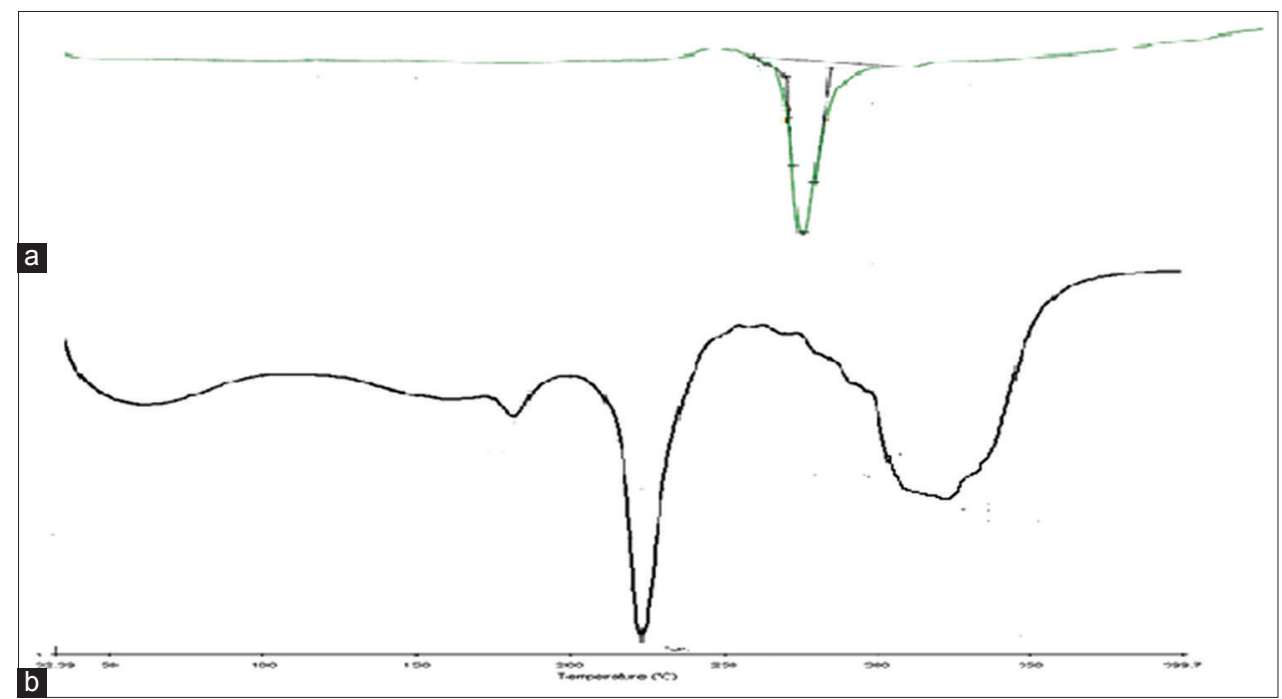

Fig. 2: Differential scanning calorimetry thermogram of (a) metformin hydrochloride (b) coated metformin granules 3 
Table 1: Formulation composition for metformin-loaded granules

\begin{tabular}{llllll}
\hline Formulation code & Drug $(\mathbf{m g})$ & Ethyl cellulose $\mathbf{( m g )}$ & Di- calcium phosphate $(\mathbf{m g})$ & HPMC K100M $(\% \mathbf{w} / \mathbf{w})$ & Total \\
\hline MG1 & 500 & 0 & 100 & 7.5 & 600 \\
MG2 & 500 & 10 & 90 & 7.5 & 600 \\
MG3 & 500 & 20 & 80 & 7.5 & 600 \\
MG4 & 500 & 70 & 60 & 7.5 & 600 \\
MG5 & 500 & 40 & & 7.5 & 600 \\
\hline
\end{tabular}

HPMC: Hydroxypropyl methylcellulose

Table 2: Flow properties of metformin granules

\begin{tabular}{llllll}
\hline Formulation codes & Angle of repose $\left(\theta^{\circ}\right)$ & Bulk density $\left(\mathbf{g} / \mathbf{c m}^{\mathbf{3}}\right)$ & Tapped density $\mathbf{( g / \mathbf { c m } ^ { 3 } )}$ & Hausner's ratio & Carr's index $(\mathbf{\%})$ \\
\hline MG1 & 21.76 & 0.397 & 0.428 & 1.07 & 7.24 \\
MG2 & 0.416 & 0.432 & 1.03 & 3.70 \\
MG3 & 26.54 & 0.425 & 0.447 & 1.05 & 4.54 \\
MG4 & 23.74 & 0.390 & 0.430 & 1.10 & 9.30 \\
MG5 & 20.30 & 0.421 & 0.443 & 1.05 & 4.96 \\
\hline
\end{tabular}

Table 3: Percentage yield and drug content

\begin{tabular}{lll}
\hline Formulation code & Percentage yield (\%) & Drug content (\%) \\
\hline MG1 & 79.26 & 78.23 \\
MG2 & 80.4 & 84.68 \\
MG3 & 81.66 & 96.62 \\
MG4 & 82.86 & 92.38 \\
MG5 & 77.66 & 86.25 \\
\hline
\end{tabular}

Where

$\mathrm{Q}_{\mathrm{t}}$ is the amount of drug released at time $\mathrm{t}$;

$\mathrm{Q}_{0}$ is the initial amount of the drug in the formulation;

$\mathrm{k}_{0}, \mathrm{k}_{1}, \mathrm{k}_{\mathrm{H}}$, and $\mathrm{k}_{\mathrm{HC}}$ are release rate constants for zero-order, first-order, Higuchi model, and Hixson-Crowell rate equations.

$\mathrm{M}_{\mathrm{t}}$ is the amount of drug released at time $t$,

$M_{\infty}$ is the amount of drug released at time $\infty$;

$\mathrm{k}$ is the kinetic constant,

$\mathrm{n}$ is the diffusion coefficient.

The release data of various formulations were fitted in various models to ascertain the mechanism of drug release $[11,12]$.

\section{RESULTS AND DISCUSSION}

Preparation of sustained release matrix granules

Different batches of granules (MG1, MG2, MG3, MG4, and MG5) were prepared according to the composition mentioned in Table 1.

\section{Compatibility studies}

\section{FTIR analysis}

The IR spectrum of metformin hydrochloride showed the existence of characteristic peaks corresponding to the functional groups present in the drug structure. IR spectra of metformin hydrochloride peaks were found at $1062.3 \mathrm{~cm}^{-1}$ (C-N stretching), 3367.0/cm (NH stretching), $1623.3 / \mathrm{cm}$ ( $\mathrm{C}=0$ stretching), and $2151.5 / \mathrm{cm}$ (azide group). The presence of any interaction between drug and polymers used often leads to significant changes in IR spectra of the drug-polymer mixture. From the IR spectra of drug-polymer mixture, it was found that there occurred no major shift in the frequencies of the characteristics functional groups of the drug. The absence of significant shifting in intensity of peaks and bandwidth of the excipients showed that no incompatibilities occurred between the drug and polymers used.

\section{$D S C$}

DSC thermogram of metformin hydrochloride (Fig. 2) showed a sharp endothermic peak at $231.03^{\circ} \mathrm{C}$ corresponding to its melting point. The obtained value matched with the value given in literature. In the DSC

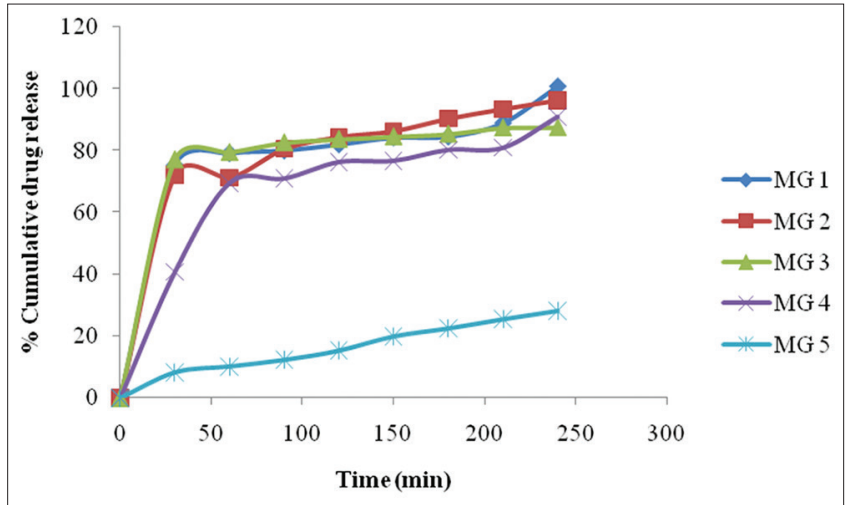

Fig. 3: In vitro release of uncoated drug release

curve of metformin hydrochloride granules, the original peaks were retained and no additional peaks were obtained. This indicated that metformin hydrochloride with other polymers has better compatibility.

\section{Characterization of granules}

\section{Determination of micromeritic properties}

Flow properties such as angle of repose, bulk density, tapped density, Carr's index, and Hausner's ratio of the granules mentioned in Table 2. The bulk density of granules was found to be between 0.39 and $0.425 \mathrm{~g} / \mathrm{cm}^{3}$, tapped density was 0.447 and $0.43 \mathrm{~g} / \mathrm{cm}^{3}$, Carr's index was found to be between 4.54 and $9.30 \%$, Hausner's ratio was 1.04 and 1.10 , and angle of repose was found to be 23.74 and $20.30^{\circ}$. The flow properties of different batches of granules were excellent as the angle of repose values were found to be $<25$, compressibility index $<15 \%$, and Hausner's ratio $<1.25$ in case of all the batches.

\section{Percentage Yield (\% yield)}

Percentage yield of different batches was in the range of 77.66-82.86\%. All the batches of granules showed more than $75 \%$ yield.

\section{Estimation of drug content}

The drug content for all the formulations was found to be in the range of $78.23-96.62 \%$ as shown in Table 3. These values indicated uniformity of drug content in each batch of granules.

Determination of particle size distribution by sieve analysis Particle size distributions of various formulated batches of microspheres (Table 4) were found to be within a lean dimension (i.e.,605-1205 $\mu \mathrm{m}$ ). A major fraction of the granules (75-85.43\%) in 
Table 4: Size distribution analysis of metformin granules

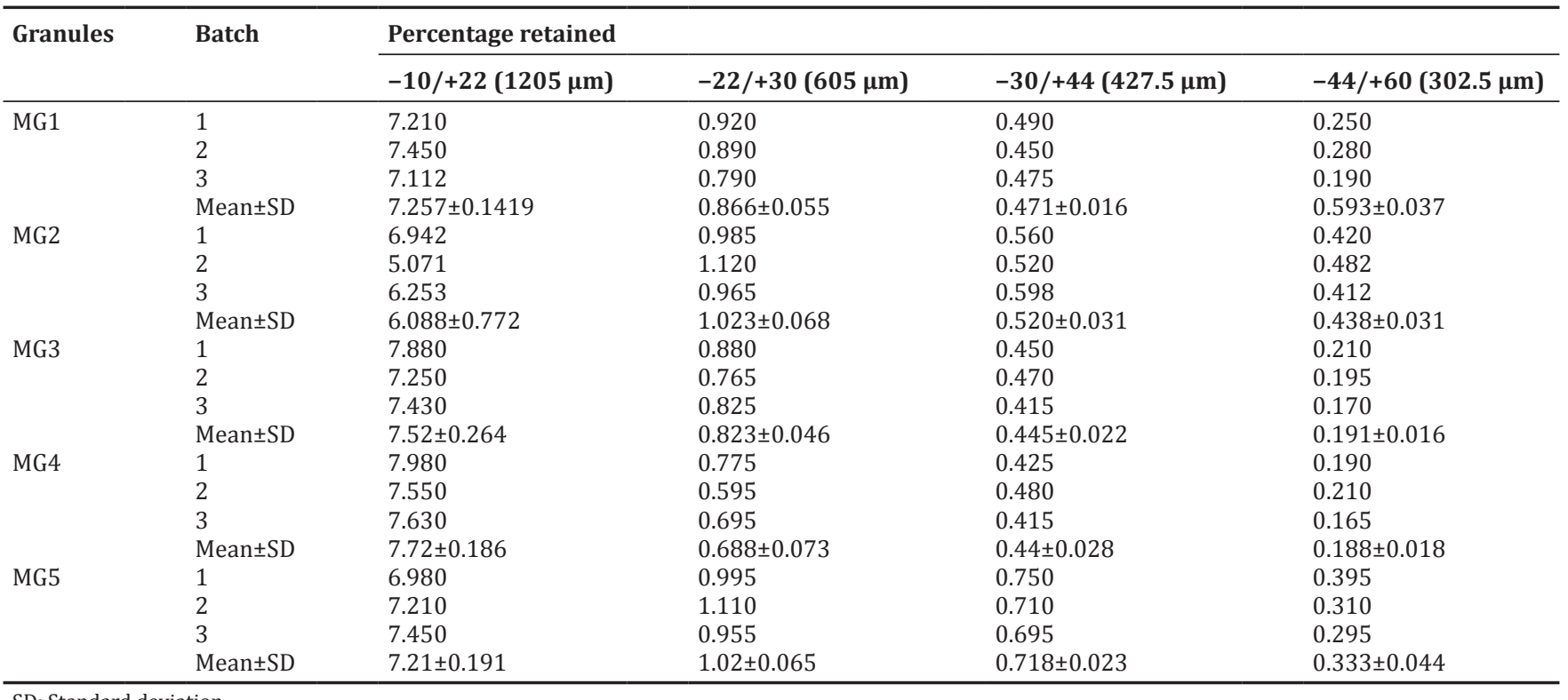

SD: Standard deviation

Table 5: Cumulative percent drug release data of uncoated granules for the selection of formulation for coating

\begin{tabular}{|c|c|c|c|c|c|}
\hline \multirow[t]{2}{*}{ Time (min) } & \multicolumn{5}{|c|}{$\%$ cumulative drug release } \\
\hline & MG1 & MG2 & MG3 & MG4 & MG5 \\
\hline 30 & $75.46 \pm 0.67$ & $73.19 \pm 1.36$ & $77.18 \pm 1.36$ & $40.86 \pm 0.32$ & $8.35 \pm 0.31$ \\
\hline 60 & $79.25 \pm 0.25$ & $79.2 \pm 1.98$ & $79.54 \pm 1.10$ & $69.59 \pm 0.54$ & $10.25 \pm 0.25$ \\
\hline 90 & $80.12 \pm 0.39$ & $80.55 \pm 0.65$ & $82.64 \pm 0.96$ & $71.04 \pm 0.62$ & $12.36 \pm 0.24$ \\
\hline 120 & $82.08 \pm 0.45$ & $84.38 \pm 0.98$ & $83.75 \pm 0.34$ & $76.44 \pm 0.12$ & $15.35 \pm 0.66$ \\
\hline 150 & $84.30 \pm 0.65$ & $86.26 \pm 0.21$ & $84.6 \pm 0.41$ & $76.81 \pm 0.98$ & $19.98 \pm 0.22$ \\
\hline 180 & $84.60 \pm 1.98$ & $90.34 \pm 0.36$ & $85.42 \pm 0.49$ & $80.33 \pm 0.62$ & $22.56 \pm 0.98$ \\
\hline 210 & $89.00 \pm 0.39$ & $93.44 \pm 0.99$ & $87.43 \pm 1.42$ & $81 \pm 0.24$ & $25.52 \pm 0.65$ \\
\hline 240 & $100.89 \pm 1.25$ & $96.27 \pm 1.96$ & $87.56 \pm 1.65$ & $91.05 \pm 0.99$ & $28.25 \pm 0.19$ \\
\hline
\end{tabular}

Mean \pm SD, $n=3$. SD: Standard deviation

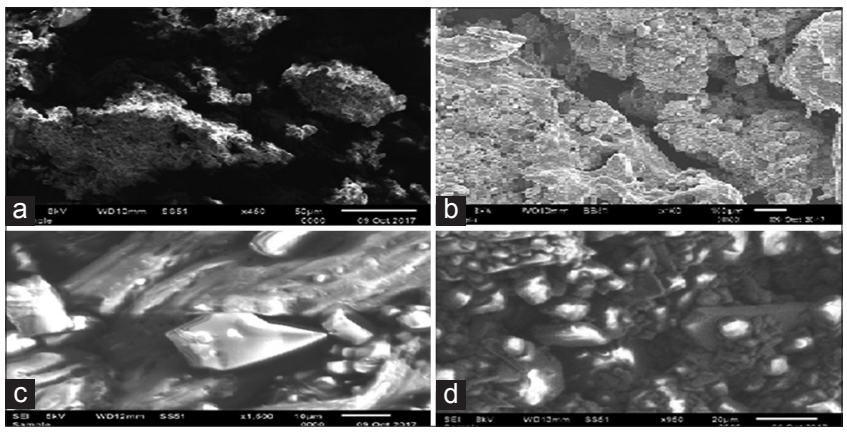

Fig. 4: Scanning electron microscopy images of (a) metformin hydrochloride, (b) uncoated granules, (c) and (d) coated granules

case of all the formulated batches were within a range of $-10-+22$ (i.e., $1205 \mu \mathrm{m}$ ) mesh size.

\section{In vitro drug release studies}

The cumulative in vitro release studies of different formulations of metformin (MG1-MG5) were performed in $\mathrm{pH} 6.8$ phosphate buffer for $4 \mathrm{~h}$. The samples were spectrophotometrically analyzed at $235 \mathrm{~nm}$ and the values mentioned in Table 5. The results (Fig. 3) showed that in case of formulations MG3 and MG4, the concentration of polymers used showed retardation in the drug release. To further sustain the release of drug over a longer period of time, these batches of granules were coated further with retardant polymers.

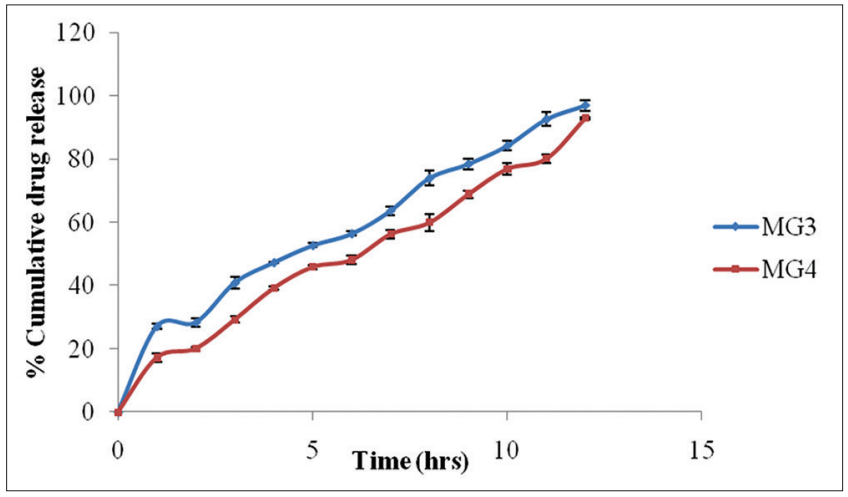

Fig. 5: Dissolution data for coated granules. Mean \pm standard deviation, $n=3$

\section{Surface morphology}

The SEM photographs of metformin hydrochloride (Fig. 4) indicated that the drug was crystalline in nature. SEM photographs of optimized formulation consisting of uncoated metformin granules indicated that these were discrete and free flowing. These photograph studies of the coated granules indicated that granules were spherical with smooth surface and completely covered with the polymer coat.

In vitro drug release studies of coated granules

The cumulative in vitro release studies of CMG3 and CMG4 were performed in $\mathrm{pH} 6.8$ phosphate buffer, and samples were 
spectrophotometrically analyzed at $235 \mathrm{~nm}$. The values were mentioned in Table 6. It was found that CMG3 (Fig. 5) showed a better sustainable drug release of $97.02 \%$ within $12 \mathrm{~h}$.

\section{Kinetics of drug release}

Release data were analyzed as per zero-order, first-order, Higuchi, and Korsmeyer-Peppas equation models to assess the probable drug release kinetics from the coated granules. The values were shown in Table 7.

Analysis of the release data as per different kinetic models (Fig. 6) indicated that metformin release from these granules was best fit toward zero-order kinetics. Correlation coefficient $\left(\mathrm{r}^{2}\right)$ values in the zero-order models were higher than those in the first order, indicating that the drug release was independent of drug concentration.
Correlation coefficient $\left(\mathrm{r}^{2}\right)$ values in Higuchi model suggests that the release of drug was following diffusion type of mechanism which is generally seen in case of swellable matrices.

\section{CONCLUSION}

From the results, we can conclude that design of coated granules employing polymers mentioned above showed a better-sustained release of metformin hydrochloride for $12 \mathrm{~h}$.

\section{ACKNOWLEDGMENT}

The authors would like to thank Dr. P. Udaya Shankar, Principal, Maharajah's College of Pharmacy, Vizianagaram, for providing required facilities to carry out this research work. We are also thankful to Mr. Ranjit Prasad Swain, Assistant Professor, Maharajah's College of

Table 6: Dissolution data of coated metformin granules

\begin{tabular}{llr}
\hline \multirow{2}{*}{ Time (h) } & \% Cumulative drug release & \\
\cline { 2 - 3 } & CMG3 & CMG4 \\
\hline 1 & $27.1 \pm 0.98$ & $17.25 \pm 1.35$ \\
2 & $28.4 \pm 1.36$ & $20.13 \pm 0.36$ \\
3 & $40.92 \pm 1.98$ & $29.24 \pm 0.94$ \\
4 & $47.31 \pm 0.25$ & $39.19 \pm 0.35$ \\
5 & $52.70 \pm 0.68$ & $45.89 \pm 0.64$ \\
6 & $56.42 \pm 0.72$ & $48.12 \pm 1.34$ \\
7 & $63.71 \pm 1.35$ & $56.25 \pm 1.43$ \\
8 & $74.02 \pm 2.35$ & $59.92 \pm 2.64$ \\
9 & $78.51 \pm 1.64$ & $68.89 \pm 1.26$ \\
10 & $84.30 \pm 1.65$ & $76.92 \pm 1.79$ \\
11 & $92.64 \pm 2.10$ & $80.09 \pm 1.34$ \\
12 & $97.02 \pm 1.67$ & $92.89 \pm 0.36$ \\
\hline
\end{tabular}

Table 7: Data of release kinetics study

\begin{tabular}{|c|c|c|c|c|c|c|c|c|c|c|}
\hline \multirow[t]{2}{*}{ Formulation code } & \multicolumn{2}{|c|}{ Zero order } & \multicolumn{2}{|c|}{ First order } & \multicolumn{2}{|c|}{ Higuchi model } & \multicolumn{2}{|c|}{ Hixson-Crowell } & \multicolumn{2}{|c|}{ Korsmeyer's-Peppas } \\
\hline & $\mathbf{r}^{2}$ & $\mathrm{~K}_{\mathbf{0}}$ & $\mathbf{r}^{2}$ & $K_{1}$ & $\mathbf{r}^{2}$ & $\mathbf{K}_{\mathrm{H}}$ & $\mathbf{r}^{2}$ & $\mathbf{k}$ & $\mathbf{r}^{2}$ & $N$ \\
\hline MG1 & 0.519 & 0.255 & 0.928 & 0.003 & 0.765 & 5.168 & 0.942 & 0.003 & 0.882 & 0.814 \\
\hline MG2 & 0.541 & 0.263 & 0.926 & 0.008 & 0.796 & 5.331 & 0.785 & 0.009 & 0.893 & 0.819 \\
\hline MG3 & 0.412 & 0.219 & 0.967 & 0.002 & 0.688 & 4.727 & 0.622 & 0.005 & 0.870 & 0.806 \\
\hline MG4 & 0.692 & 0.284 & 0.847 & 0.006 & 0.903 & 5.424 & 0.839 & 0.006 & 0.935 & 0.816 \\
\hline MG5 & 0.981 & 0.164 & 0.980 & 0.002 & 0.961 & 2.714 & 0.830 & 0.015 & 0.997 & 0.673 \\
\hline CMG3 & 0.968 & 7.201 & 0.847 & 0.249 & 0.974 & 27.91 & 0.936 & 0.233 & 0.958 & 0.558 \\
\hline CMG4 & 0.986 & 6.975 & 0.850 & 0.181 & 0.951 & 26.46 & 0.928 & 0.193 & 0.974 & 0.705 \\
\hline
\end{tabular}

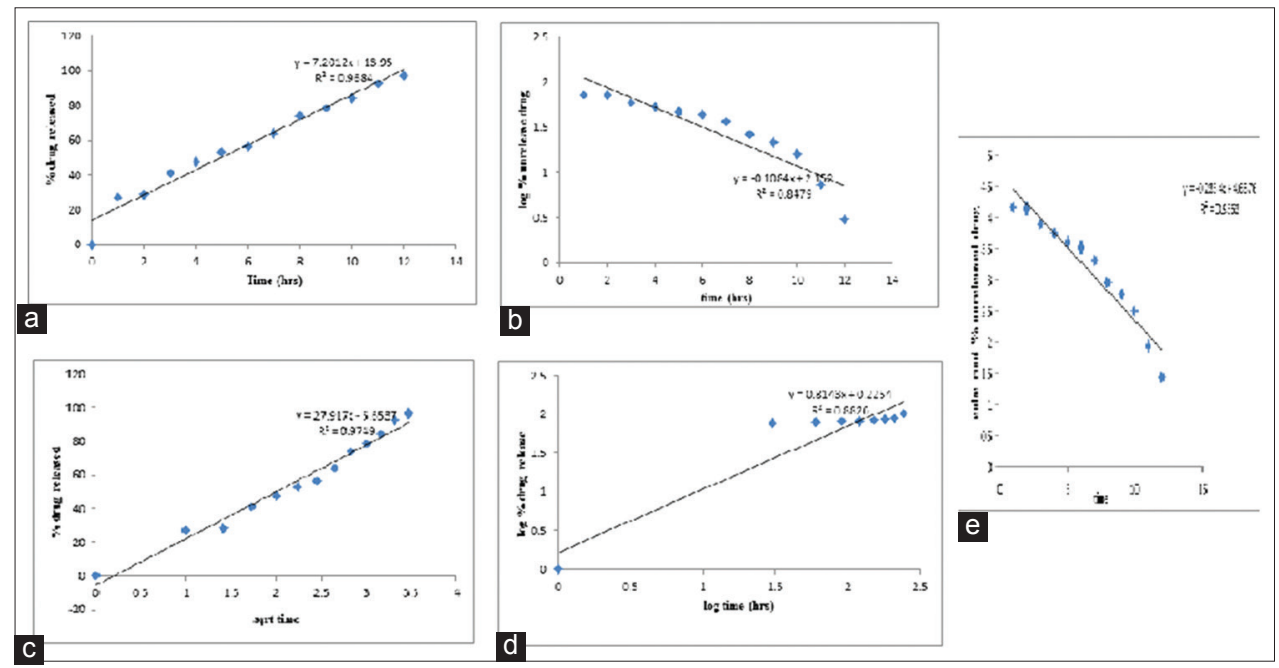

Fig. 6: Kinetics of drug release (a) zero order, (b) first order, (c) Higuchi model, (d) Korsmeyer-Peppas, (E) Hixson-Crowell 
Pharmacy, Vizianagaram, for his support and encouragement during this work

\section{CONFLICTS OF INTEREST}

The authors have no conflicts of interest.

\section{REFERENCES}

1. Onyechi1 JO, Okafo SE. Evaluation of carnauba wax in sustained release Diclofenac sodium tablet formulation. J Chem Pharm Res 2016;8:714-21.

2. Raveendra P, Kanchan K, Birendra S. Compression and evaluation of extended release matrix pellets prepared by the extrusion/ spheronization process into disintegrating tablets. Braz J Pharm Sci 2012; $48: 117-29$

3. Sayed IA, Gamal MM, Mahmoud EB. Formulation and evaluation of sustained release tablets of Metformin hydrochloride using hydrophilic synthetic and hydrophobic natural polymers. Indian J Pharm Sci 2011;73:208-15

4. Barnabas W, Patel PB, Moothandassery SS, Josephine LJ, Brahmani PS. Sustained release enteric coated tablets of pantoprazole: Formulation, in vitro and in vivo evaluation. Acta Pharm 2013;63:131-40.

5. Radha RE, Vinod KT, Lakshmi UA. Enhancement of dissolution rate and physicochemical characterization of Irbesartan inclusion complexes using cyclodextrins. Res J Pharm Tech 2017;10:301-6.

6. Reetika C, Kammal PK, Neena B. Colon specific delivery of eudragit e-100 and eudragit-FS30D coated tablets of leflunomide using chitosanchondroitin sulphate inter polymer complex. Int J Pharm Pharm Sci 2015;7:286-91.

7. Hetal P, Sonia P, Vihari P, Ritesh S, Sanjay T. Pulsatile release of ketoprofen from compression coated tablets using eudragit ${ }^{\circledR}$ polymers. Int J Pharm Pharm Sci 2016;8:224-9.

8. Anirbandeep B, Tin WW, Navjot S. Formulation development and optimization of sustained release matrix tablet of Itopride $\mathrm{HCl}$ by response surface methodology and its evaluation of release kinetics. Saudi Pharm J 2013;21:201-13.

9. Venkateswara RB, Navaneetha G. Formulation development and in vitro evaluation of gastro retentive floating microspheres of Verapamil hydrochloride. J Pharm Sci Innov 2015;4:183-9.

10. Prakash G, Shashikanth R, Hiremath D, Rajgopal U. Development and in vitro characterization of esomeprazole floating gastro retentive microspheres. J Appl Pharm Sci 2013;3:71-7.

11. Suvakanta D, Narasimha MP, Lilakanta N, Prasanta CH. Kinetic modeling on drug release from controlled Drug delivery systems. Acta Pol Pharm Drug Res 2010;67:217-23.

12. Ramteke KH, Dighe PA, Kharat AR, Patil SV. Mathematical models of drug dissolution: A review. Sch Acad J Pharm 2014;3:388-96. 